Sharper, better, faster, stronger: Performing Northern masculinity and the legacy of Sean Bean's Sharpe

Siân Harris, University of Exeter

\begin{abstract}
This article examines the career of Sheffield-born actor Sean Bean through an analysis of his starring role in the ITV historical drama Sharpe (1993-2008). I chart the ways in which the adaptation capitalizes on Bean's public identity as a Northern English, working-class actor, as well as providing a specific emphasis on regionality through a focus on how the characterization speaks to a popular understanding of Yorkshire, and a consideration of how Bean's subsequent roles have engaged with Sharpe's legacy. I posit that this performance catalyses Bean's star persona, and offers a revealing insight into the preconceptions about Northern English identity and culture on-screen.
\end{abstract}

\title{
Keywords
}

historical drama

masculinity

Northernness

TV

Sean Bean

Napoleonic Wars 
As one of Sheffield's most successful exports, actor Sean Bean has established an impressive career in film and television, from the obligatory minor appearance in The Bill (1984-2010) to an Emmy Award-winning performance in The Accused (2010-2012). He has taken on a range of roles in literary adaptations, Hollywood blockbusters and action thrillers, but is arguably best known for playing villains and dying on-screen. Bean's characters have been variously shot, stabbed, drowned, beheaded, quartered, crushed, frozen, exploded and stampeded to death by cows. A YouTube compilation of his many deaths has attracted over 1.7 million views, and the producers of his current television series Legends (2014-) made the hashtag \#DontKillSeanBean the central focus of an intensive promotional campaign. Given this reputation for terminal mortality, it is somewhat ironic that Bean's breakthrough role came with the character of Richard Sharpe. Sharpe was a hero of the Napoleonic Wars, the star of sixteen feature episodes, and, perhaps most importantly, not killed off at the end. Based on Bernard Cornwell's best-selling historical novels, the Sharpe series originally ran on ITV from 1993 to 1997, with two special episodes in 2006 and 2008. Crucially, Sharpe not only established Bean's star profile but also reflected and capitalized on his Yorkshire roots, and so the series provides the ideal forum in which to explore the enduring significance of Sean Bean's Northern identity.

The original novels chart Sharpe's progress through the ranks of the British Army, from Private to Lieutenant Colonel. At a time when officer ranks were usually the preserve of the socially and financially privileged, Sharpe is a working-class outsider who gains his promotion through merit and bloody-minded determination. In the early books, the character is described as a dark-haired Londoner, born in Wapping and raised in a foundling home on 
Brewhouse Lane. Cornwell would go on to amend this, and the new biography is succinctly explained in Sharpe's Prey: 'He had run from London, gone to Yorkshire, murdered, joined the army to escape the law and there found a home' (2001: 36). This act of responsive readaptation is quite remarkable, but also in keeping with Cornwell's generally high opinion of Bean's performance, as he notes in the essay Sharpe's Story: 'The greatest compliment I can pay Sean, other than saying that I like him hugely, is that he really did take over Sharpe. I hear Sean's voice when I write Sharpe' (2006: 55). It seems that even to his creator, Sharpe now speaks with a Yorkshire accent.

Cornwell was not the only viewer to be impressed. At its peak, Sharpe attracted viewing figures of ten to twelve million, and DVD sales have registered in the hundreds of thousands. The original Sharpe episodes are undeniably formulaic, but it is a finely tuned and effective formula, as Sharpe is beset by inept officers, wily enemies and beautiful women. Bean's commanding performance is supported by a strong ensemble cast, including Daragh O’Malley as Sharpe's sidekick Patrick Harper, and the acclaimed folk musician John Tams as Rifleman Daniel Hagman. The popularity of the series was also supported by a range of merchandize and memorabilia, ranging from clocks to cook books, and meticulously detailed guides to the events that inspired the stories. Mark Adkin's The Sharpe Companion (1998) and The Sharpe Companion: The Early Years (2003) are promoted as 'historical and military guides' and come complete with maps, glossaries and comprehensively combined timelines. For example, the entry for 1777 provides Sharpe's putative date of birth, alongside details of the American War of Independence beneath the heading 'Other Events' (Adkin 2003). In The Historical Novel, Jerome De Groot calls attention to the ways in which this range of extratextual material, designed to engage the fan community, also helps to foster an appealing illusion of authenticity: 'This interleaving of the historical and fictional [...] serves a need for 
authentification amongst the readership of the novels. It also introduces a key meta-fictional element to the series. They have a manifestation outside of their imaginative universe' (2010: 84-85). I posit that Bean's portrayal of Sharpe can be read as the ultimate embodiment of this desire towards authenticity, both in terms of performance and reception. This reading is instigated by a consideration of how far Bean's performance establishes the character by playing strategically to and away from cultural preconceptions about working-class Northern masculinity. The analysis is sustained through a closer reading of the complexities of regional identity, with a distinct focus on Yorkshire, and the key episode 'Sharpe's Justice' (1997). I will also address the extent to which the legacy of Sharpe has shaped Bean's media profile and the public perception of him as a Northern English actor. Throughout then, this article will interrogate both Bean's performance as Sharpe and the way in which the role has reciprocally influenced his star persona.

\section{Sharpe's Identity}

Given the extent to which Bean has become synonymous with the tough and talented Napoleonic soldier, it is rather disconcerting to remember that the role of Sharpe originally belonged to Paul McGann. McGann had won the part after screen tests against Rufus Sewell; Bean was not even on the shortlist. Two days into filming though, McGann fell and injured himself when playing football between takes, tearing a ligament in his knee, which would take the best part of a year to heal. The accident resulted in one of the largest insurance claims in British television history (over $£ 2$ million) and, with Bean recruited as a last-minute replacement, a very different interpretation of Richard Sharpe. There appears to be no available footage of McGann's performance, but photographs suggest his Sharpe was dashing and elegant, with Byronic dark curls, full sideburns and a well-fitting uniform. Because of 
budget and time constraints that uniform was hastily altered rather than replaced, and so the second Sharpe immediately cut a rather less groomed figure on-screen, with the 5 ' $10 \frac{1}{2}$ " Bean strapped into a jacket tailored for the 5, $8 \frac{1}{2}$ " McGann. Tellingly, the difference between the two performances has been frequently read in terms of contrasting models of masculinity. Recurring Sharpe guest star Julian Fellowes noted that 'Paul had then a certain delicacy of feature that unavoidably gave him a Dandini-esque quality when he was in the uniform. Sean is what used to be called "a real man" in that his camera presence cannot be softened' (quoted in Jackson 2000: 116), while David Troughton, who played Sir Arthur Wellesley for the first two episodes, has said that 'Paul and Sean had different approaches. Paul's was more a romantic hero, whereas Sean gave Richard Sharpe a Northern hard edge' (quoted in Jackson 2000: 116). This perceived divide between the possibility of a refined, romantic Sharpe versus the reality of Bean's more rugged interpretation is crucial to my reading of the character, as the actor's Northern English identity is immediately associated with toughness and a more 'authentic' brand of masculinity.

Of course, it was Bean's late arrival to the production that actually led to Sharpe's most distinguishing feature, as it was agreed he should perform with his own accent. This was primarily because of time constraints and the pressure of delivering a consistent performance at relatively short notice, as explained by director Tom Clegg:

He really had enough to do without having to sustain an accent in such a long-running series. I had heard his London accent in Fool's Gold and it was okay, but I thought that the earthy quality of Richard Sharpe would be better served by Sean's natural accent. (quoted in Jackson 2000: 110)

Comment [sh1]: Confirmed, thank you

Comment [K2]: As per journal style, quotes with more than 45 words are to be set as display quotes. Hence, please confirm the change from text to display quote. 
Although Clegg's 'okay' is hardly a glowing recommendation for Bean's vocal range, it is worth noting that he had actually delivered a range of different accents during his pre-Sharpe career, including the cut-glass tones of the villainous aristocrat, Lovelace, in the BBC's 1991 adaptation of Clarissa. The cinematographer for that production, John McGlashan, reported that 'He was very good on the English accent but whenever a take was over he would instantly revert to his Northern accent' (quoted in Jackson 2000: 82). This apparently unthinking distinction between 'English' and 'Northern' suggests the full extent of the perceived divide between the presumed standard of a Southern English identity and the implied deviation of a Northern one. Therefore, while the decision for Bean to keep his accent was initially made for pragmatic reasons, it clearly has a more complex affect. The accent confers a sense of toughness and restraint as well as generating a heightened sense of reality, both in terms of the connection it establishes between the actor and the character and through evoking a long-standing cultural trend to read Northern identities - particularly working-class male identities - as more authentic than their upper-class counterparts. As George Orwell surmises in The Road to Wigan Pier, "[t]he Northerner has "grit", he is grim, "dour", plucky, warm-hearted, and democratic; the Southerner is snobbish, effeminate, and lazy' (2001: 101). This mutually reductive mythology is pivotal throughout Sharpe, where it quickly becomes functional shorthand to explain and explore the tense relationships between Sharpe and his fellow officers.

Writing in a new introduction for Sharpe's Eagle, Cornwell explains that although he originally assumed his main antagonists would be French, 'the circumstances of war meant that Sharpe spent much more time with the British [...] and if he was to be unendingly 
challenged, irritated, obstructed and angered then the provocations had to come from people with whom he was constantly associated' (1994: vii). The result is that the Sharpe novels are far more concerned with conflict within the British ranks, and that conflict is inevitably shaped by the politics of social class. And while the contrast between the speech of a working-class Londoner and an upper-class officer would, of course, be immediately evident, the necessary tension is infinitely exacerbated through Bean's performance, which delivers the added subtext of a north/south divide. His flat vowels and gruff tones are contrasted against the cut-glass accents and affected speech patterns of his more privileged colleagues, and this is frequently used to signal their villainy. For example, in the adaptation of Sharpe's Eagle, the unpleasant duo of Lieutenants Gibbons (Neil Dudgeon) and Berry (Daniel Craig) punctuate their conversation with exclamations of 'old boy' (24 times), 'I say' (seven times) and, for variety, 'old chap' (twice). The lexical reinforcement verges on caricature, but is nevertheless effective in underlining difference. It can also be seen to serve a more complex purpose. Popular historical fiction can easily be accused of promoting a simplistic, if not outright, jingoistic agenda, as De Groot suggests when he describes the Sharpe series as 'offer[ing] a very uninflected version of events' (2010: 168). As a reading of the books, it is debateable, but it does serve to underline the narrative value of further distancing television Sharpe from the conventional model of an English officer, and keeping the primary focus on social rather than international disputes. The real drama certainly lies not in British victories against the French, but in Sharpe's victories against the British establishment. Blandford perceives this as another point of contact between actor and character, suggesting that 'Sean's Sharpe is "other" as, in some strange way, is Sean Bean himself' (2006: 217). Bean's Northern English identity is credited here as a point of marginalization, which is inextricably transferred to Sharpe. 
However, as important as the delivery of his words might be, Sharpe is still primarily a man of action. Bean's presence is highlighted in terms of allure as well as menace, and the combination is essential to the series' success. First, Bean has to be credible as a fierce soldier, who is in his element on the battlefield, and has an instinctive aptitude for combat. Cornwell perhaps articulates this vision most vividly in Sharpe's Triumph, when Sharpe rescues Wellesley (later Lord Wellington) during the Battle of Assaye:

He was keening a mad noise as he fought and it seemed to him at that instant as though he could do nothing wrong. It was as if the enemy had been magically slowed to half speed and he had been quickened. He was taller than any of them, and he was stronger, and he was suddenly much faster. He was even enjoying the fight, had he known anything of what he felt, but he only sense the madness of battle. (1998: 264)

Bean's interpretation is not quite this frenzied, but consistently delivers in terms of compelling physical force, as the fight choreography focuses on the corporeal impact of violence. In a vicious, albeit ultimately friendship-establishing fight between Sharpe and Harper in 'Sharpe's Rifles' (1993), the actors are shown staggering between increasingly wild blows, their ragged breath is heavy on the audio track, and Harper vomits directly in front of the camera after Sharpe smashes his face. It is an unflinchingly brutal scene that sets the tone for the series, as Sharpe's frequent duels and grudge-matches are characterized by the same physical intensity. Bean won medals for fencing during his time at RADA, and this expertise is invaluable to his portrayal of Sharpe - Sharpe lacks the formal training taken for granted by the officer class, and is rarely the most talented swordsman - and so Bean's skill is evident not in his ability to appear the best but from his ability to appear technically 
outclassed and still emerge convincingly victorious. In 'Sharpe's Honour' (1994) he is challenged to a duel by the aristocratic Marqués de Casares el Grande, and initially struggles to match the Marqués' precision and speed. After receiving a cut on his face, Sharpe abandons duelling etiquette and delivers a vicious kick below the belt, followed by hacking blows with the sword and a knock-out punch to the jaw. The shift in style serves to make the Marqués's technical talent immaterial, as street-fighting wins out against elite martial art. In a different drama, Sharpe's behaviour would be presented as reprehensible cheating; here, it is simply a triumph of pragmatism.

Sharpe's inferior social standing is offset by physical prowess and superior strength, but the character has to be attractive as well as aggressive. 'Sharpe's Rifles' first aired in May 1993, and in June of the same year Bean's profile was raised again by his turn as Mellors in Ken Russell's miniseries of Lady Chatterley_(1993). This combination of roles resulted in a new degree of media exposure, and successfully launched the image of Bean as a sex symbol. His working-class background and the connection with Lady Chatterley further served to establish a particularly rugged and roughly hewn appeal. A Daily Express profile described Bean as 'handsome, lean and capable of looking quite mean [...] the former welder who has become one of the hottest actors of his generation' (Forwood 1993), while Time Out waxed lyrical about his "unnerving raw masculinity [...] it was called "animal magnetism" in the days before aftershave' (Paterson 1993). These comments_alse-echo Julian Fellowes' earlier description of Bean as a 'real man', and at first glance it does seem that Sharpe celebrates a blatantly unreconstructed brand of masculinity. But while this image is bolstered by class, it is also a complicating factor. Sharpe's love interests are frequently upper-class women, placing him as the 'bit of rough'. In 'Sharpe's Regiment' (1996) Sharpe is picked up by the elegant Lady Anne Camoynes (Caroline Langrishe), who hints at valuable information but 
refuses to confide, and insists he leave by the back stairs. Sharpe's retort, 'You clawed at me. Dug your nails in my back. Used me', is delivered with a raw and palpable resentment. Furthermore, when Sharpe's second wife Jane (Abigail Cruttenden) leaves him for the fashionable Lord Rossendale, she complains that 'You're an animal. All you can do is kill. John doesn't have to have a sword in his hand to be a man [...] He knows how to talk'. Sharpe's strongest relationships are actually with a Spanish guerrilla leader, Teresa (Assumpta Serna), and a French farmer, Lucille (Cécile Paoli), both of whom offer an alternative to the perils of negotiating a relationship across the British class system. ${ }^{1}$ The first impression of Sharpe may be of a straightforwardly swashbuckling drama, but the interplay of class, physical violence and sexuality combines to provide a more multifaceted and intriguing narrative, underpinned by Bean's performance.

\section{Sharpe's Yorkshire}

A further component of that performance is, of course, a specifically Yorkshire identity. Northernness and Yorkshireness are obviously closely connected but the terms are not interchangeable, and Bean's role in Sharpe highlights the intricacy of this distinction. As Dave Russell observes in Looking North: Northern England and the National Imagination, Yorkshire has been most influential in shaping the way in which the north is identified and understood: 'Yorkshire has enjoyed a deserved reputation for an especially intense county pride, and one probably established earlier than elsewhere in the region [...] It has certainly imposed itself and been imposed upon the characterisation of the North' (2004: 38). Russell's reading suggests a palimpsestic quality at work, as Northern and Yorkshire identities are mutually inscribed, but also present as separate layers of meaning. Reimagining Sharpe as a 
Yorkshireman therefore means engaging with a history of regional stereotypes that adds pertinent new depths and dimensions to the character:

For a long time, the North has been held up as a beacon of the underdog: grim, industrial and dour. Yorkshire's industrial cities, hard work ethic, tendency towards self-depreciation, rustic charm, overt masculinity, suspicion of strangers and, above all else, pride, capture much of what the region is about. (Fletcher 2012: 202)

Fletcher's definition echoes key aspects of Sharpe's character, which, although already present in the books, were certainly intensified by the screen portrayal. The emphasis both Russell and Fletcher place on regional pride is supported throughout Bean's promotional interviews, which inevitably include some mention of his ' $100 \%$ Blades' tattoo, and his enduring affection for his home town of Sheffield: 'Rather than sipping champagne in sophisticated restaurants, you imagine him with a pint of bitter in a working men's club in his native Yorkshire. For all the fame that the capricious world of show business has bestowed, he remains very close to his roots' (Staples 1995).

Yet, while the codes and cultural markers of Yorkshire may be integral to viewing Sharpe, it is actually very rare for the county itself to be mentioned. In an early scene from 'Sharpe's Rifles', Sharpe questions the men placed under his command, so that each soldier is established in terms of his origins: Cooper is a thief from Shoreditch, Hagman is a poacher from Cheshire and Harris is 'a rake and a wastrel' from Wheatley in Oxfordshire. The details help to differentiate the characters, as well as reinforcing the suggestion that the 'chosen 
men' are a unit where membership is based on individual skill, rather than a collective identity as with regiments like the South Essex or the Connaught Rangers. Despite this, Sharpe's own backstory is kept personal rather than regional. He confides to Teresa that 'I was born in a brothel. Grew up in an orphanage', but there is no reference to any location. This is quite possibly another consequence of the late casting, but it serves to further the discrepancy between the inner- and extratextual importance of the Yorkshire identity.

The county only really comes into focus in the thirteenth episode, 'Sharpe's Justice'. Unlike the majority of the Sharpe dramas, 'Sharpe's Justice' was written exclusively for television by Patrick Harbinson. ${ }^{2}$ It could indeed be argued that it was written exclusively for Sean Bean, as it further departs from Cornwell's revised story in the novels and provides a distinct backstory for the television Sharpe, establishing that in this branch of the canon he was both born and bred in Yorkshire. The episode is set in 1814, as the war in Europe is over and Sharpe is assigned to command the Scarsdale Yeomanry, a private force in the employ of mill owner Sir Willoughby Parfitt. Tensions are running high between disgruntled mill owners and their benighted workforce, and Sharpe, who grew up in the local workhouse, struggles to decide where his loyalty should lie. Throughout the episode, Sharpe's personal opinion of and connection to Yorkshire is highly ambivalent. He only accepts the assignment when it is presented as a choice between Yorkshire and Tasmania, complaining to Harper that 'I've done without Yorkshire more than twenty years and I don't want it now'. This cynical attitude neatly debunks the stereotype of the self-aggrandizing Yorkshireman, and the episode is characterized by a distinct lack of nostalgia or sentiment. 
Instead, the value of 'Sharpe's Justice' can be found through charting the ways in which the plot destabilizes social binaries, and explores the vulnerability of Sharpe's position in peacetime England. Initially, the main conflict appears predictable, as Sharpe is pitted against a young captain in the yeomanry, played with the requisite sneering menace by Douglas Henshall. In case there was any doubt about this red-coat's caddish nature, the matter seems settled by Harbinson's decision to name him George Wickham: a clear nod towards the similarly untrustworthy George Wickham of Pride and Prejudice. ${ }^{3}$ Wickham's villainy is clearly signalled, but it transpires he is not the true antagonist of the episode. Instead, the plot is driven by Parfitt (Tony Haygarth), who seeks to suppress the workers' protests while framing them for the destruction of his rivals' machines. Parfitt's agenda is masked by a bluff, straight-talking persona. He is a self-made man who claims this as a connection with Sharpe, appealing to him as one upstart to another:

And don't think they don't want to see me back down in the gutter, oh they do. The only thing that keeps me up is me money, and the fact I'm better than the lot of them. The same as you, Richard, you've shot up beyond your station, haven't you.

While previous lines of conflict have been quite clearly drawn - British/French, working class/upper class, north/south - Parfitt disrupts this narrative framework, and Sharpe is set against a fellow Yorkshireman, from a background that is only marginally less impoverished than his own. Furthermore, returning home exposes that Sharpe himself is no longer able to fit neatly into his usual role of disenfranchised outsider: to the mill workers, Major Richard Sharpe is the establishment. The Yorkshire location is essential in conveying the full scale of the change, as it calls attention to how far the character has travelled. As noted, the Sharpe 
series has been criticized for presenting a simplistic view of history, which 'emphasises duty, order, and stability - [and] rarely (despite Sharpe's maverick status) contains dissidence or complexity' (De Groot 2009: 198). The domestic, regional setting of 'Sharpe's Justice' immediately challenges this reading, as the protagonist struggles to reconcile his military duties with his personal instincts. Usually presented as a consummately capable soldier, this episode is punctuated by a series of escalating scenes in which Sharpe is increasingly helpless. He loses a humiliating public duel to Wickham, is unable to prevent the yeomanry from attacking a workers' rally and, a scant three minutes after the revelation that he has a (half-) brother, the brother is shot and killed. Even after a measure of order is restored, the overall tone remains muted.

As well as demonstrating how the series can use Sharpe's backstory as a way to draw out questions of identity and belonging, the episode thus suggests a degree of engagement with the social and psychological repercussions of war. As noted early in the episode, for the civilian population the real impact of the army's return is far from positive: 'The difference is thousands of bastard soldiers. All crawling the country, all as poor and desperate as you. Fighting you for jobs, jobs in these stinking mills [...] That's victory friends'. Various contemporary accounts also detail the ways in which soldiers struggled to adjust to peace. The Recollections of Rifleman Harris - one of the few surviving memoirs of an enlisted man - includes the note that 'I can only say, that I enjoyed life more whilst on active service, than I have even done since [...] I look back upon that portion of my time spent in the fields of the Peninsula as the only part worthy of remembrance' (Harris 1848: 237). 'Sharpe's Justice' picks up on this mood, and effectively introduces Sharpe's home in order to clarify he will never return there. Instead, the final scene has Sharpe set out alone for France and Lucille, 
and the preceding focus on his isolation means that this final rebuttal of the parochial Yorkshire stereotype is an apt conclusion.

'Sharpe's Justice' was the penultimate episode of the original run, and after the suitably bloody finale of 'Sharpe's Waterloo', the series was put on a nine-year interval. This was partly a matter of narrative logistics. Cornwell had initially written the books as a series of eleven (the same number as C. S. Forester's Hornblower), but when the television series proved popular, the author returned to the source: 'That decision was entirely venal. If a Sharpe TV series is being shown then it helps to have new Sharpe books in the shops, so back to Sharpe I went' (2006: 56). This pragmatic approach resulted in a further eleven books and two short stories, focusing on Sharpe's early career in India, his first missions in Europe, a final confrontation with Napoleon and his (admittedly rather contrived) participation in the Battle of Trafalgar. Still, adapting any of these new adventures could not be a straightforward proposition - it was one thing for Cornwell to go back in time and present a 22-year-old Private Sharpe in Sharpe's Tiger (1997), but it would have been altogether more of a stretch for Bean, who was already 38 when that book was published. There is a precedent for recasting for prequel dramas - as with Endeavour (2012-) and Rock and Chips (2010-2011) - but this does not seem to have been seriously considered, as Cornwell noted at the time: 'There was a suggestion that Sean couldn't be cast as Richard because Sharpe would be so much younger, but that would be a definite non-starter. The fans would never accept it' (quoted in Jackson 2000: 179). The eventual solution would be to rework the Indian origin story into a post-Waterloo quest, but the challenge of chronology was not the only reason for the prolonged hiatus. Bean's career was progressing and it was time to move on, but, as a final consideration of Bean's later career and media profile will show, Sharpe has proven 
instrumental not only in bringing the actor to wider attention but in continuing to shape and, more problematically, to sometimes limit his star persona.

\section{Sharpe's Legacy}

It is now more than 22 years since Bean first appeared as Sharpe, but the character retains a powerful hold on his reputation. This is at least partly because of the retroactive impact of that previously mentioned tendency to get killed off. Sharpe has become the wildcard, and gains a meta-legendary standing as ever more invincible, or, as one fan phrases it, 'Sharpe is so badass he survived Sean Bean' (Whitbrook 2014). It is_alse-worth remembering that the series has proved an inexhaustible gift to subeditors, demonstrated by such imaginative Daily Mail headlines as 'Not so Sharpe - Sean Bean looks dishevelled', 'Sean Bean lands a new girl, Sharpe-ish' and 'At the Sharpe end of a planning row: Actor Sean Bean angers neighbours with bid to create roof terrace'. Even when the pun may not be intentional, the very word has shifted meaning in any association with Bean. In Lord of the Rings: The Fellowship of the Ring (Jackson, 2001), Bean's character, Boromir, tests a blade on his fingertip and mutters 'still sharp', prompting gleeful speculation on the part of fans that this had to be a deliberate reference.

The role can also be read as having provided the perfect foundation for a succession of military characters. In 1999, Bean played SAS Sergeant Andy McNab in the TV movie Bravo Two Zero - a casting decision that McNab endorsed on the basis 'I think he could have done the job in real life' (quoted in Jackson 2000: 186). Bean later alse-appeared as Major Jack Jones in Age of Heroes (Vitoria, 2011), a film (loosely) based on the formation of Ian Fleming's commando unit in World War II. These roles resonate in light of De Groot's 
previously cited remark about the essential 'interleaving of the historical and fictional', as Bean's stint as a fictional soldier becomes the 'calling card' that legitimizes his portrayal of real persons, and fuels a perception of the actor's macho credentials.

A more recent connection back to Sharpe can be demonstrated by a consideration of Bean's role in HBO's epic fantasy adaptation Game of Thrones (2011-). Before the casting was confirmed, a speculative post on the Game of Thrones news site was not entirely persuaded by the merits of Bean: 'I've always seen him as a better actor for evil or dubious characters [...] Could he pull off the honest, honorable and loyal Lord Stark?' (Selcke 2008). When the final announcement was made, the series' original author G. R. R. Martin responded with an enthusiastic endorsement on his blog: 'Sean Bean needs no introduction. I mean, what the hell, he was Boromir and he was Sharpe, he was terrific in both roles, and in a hundred other parts besides. I can't imagine a better Ned' (2009). Bean's role in The Fellowship of the Ring demonstrates a background in high-profile fantasy that is clearly pertinent to Game of Thrones, but, at a point when the actor was more and more recognized for his villainous performances, Sharpe is the necessary reminder that Bean could ean alse-play the 'good guy'. The characters would also be connected by voice, as Game of Thrones uses regional accents to help establish the position of the different families in relation to each other, and, especially in Season 1, to pit the honest Starks in the north against the duplicitous Lannisters in the south. As highlighted by Max Read, 'it's a useful way for a dense, complicated series to quietly signal backgrounds, affiliations and alliances; it draws on pre-existing associations to quickly develop and define character' (2013), and those associations can be intertextual as well as social. In addition to supporting Bean's casting, Martin has also-often spoken of his admiration for Bernard Cornwell and enjoyment of the original Sharpe series, culminating with the two authors interviewing each other in 2012. The conversation appears in full on
Comment [K13]: The publication year of Selcke (2006) has been changed to match the publication year Selcke (2008) given in the reference list. Please confirm whether this is correct.

Comment [sh14]: 2008 is correct
Comment [K15]: Spelling of author name Max Reade has been changed to name Max Read to match the spelling in the Reference List. Please confirm whether this is correct.

Comment [sh16]: Read is correct 
both their websites, with highlights that include Cornwell cursing Martin for killing off Ned Stark.

Bean's role in Game of Thrones was just as popular with the fans as with the creators, and he has benefitted throughout his career from an undeniable degree of public affection and respect. However, he has alse-attracted some revealingly regionalist critique. In 2002, Bean took the lead role in Edward Hall's production of Macbeth at the Albery Theatre, and as with Sharpe, he played the part with his natural accent. The production met with mixed reviews plenty of praise for the pace and energy of the performance and for the dark chemistry between Bean and Samantha Bond's Lady Macbeth, but there were also-complaints that this version lacked depth and subtlety, and sacrificed real emotion for cheap entertainment. Michael Billington's review for The Guardian was firmly aligned with the latter perspective, but these potentially valid lines of criticism are rather overshadowed by his verdict on Bean:

Nothing less than a spark of genius will do for Macbeth - as Olivier, McKellen and Sher have shown down the years. What Bean offers instead is a rough-hewn, Geordie accented soldier strangely lacking in inner turmoil. This is not a man, you feel, who is prey to 'horrible imaginings' and when he cries 'Stars, hide your fires' it is with the vocal flatness of one who might be chatting to his batman. (Billington 2002) ${ }^{4}$

The response is particularly telling when contrasted against the reception of a more recent Shakespeare production, also marketed on the strength of its stars' television fame: Daniel Evans's 2011 staging of Othello at Sheffield's Crucible Theatre, which featured The Wire (2002-2008) alumni Clarke Peters as Othello and Dominic West as Iago. Although his widely publicized Eton education means that he is rarely associated with the region, West 
was actually also-born in Sheffield (he is ten years younger than Bean), and he played Iago with a Yorkshire accent. This met with general acclaim, typified by The Telegraph's review that '[West] has adopted a rough "ee bah gum" accent, a triumph of apparent trustworthiness - and a good fit for his rugged good looks, and rasping, alehouse heartiness' (Cavendish 2011). While it may be a simple question of merit, the social attitudes revealed in the respective reviews suggest uncomfortable echoes of Tony Harrison's 'Them and [uz]': 'Poetry's the speech of kings. You're one of those / Shakespeare gives the comic bits to: prose' (2013: 110). Bean's Northernness has apparently also proved a barrier to more commercial successes. In a Mail on Sunday profile, Brian Viner is dismissive of rumours that before he was cast as a Bond villain, Bean was at one stage in the running to play 007 himself: 'he could never be 007 , it wouldn't do for the actor playing Ian Fleming's smoothtalking hero to tell the world's press that he were "reet chuffed, like"" (1995). These barbs reveal a degree of lingering prejudice when it comes to actors using regional accents for certain types of roles.

In a study of typecasting, Ezra W. Zuckerman et al. neatly articulate the dilemma that faces any professional actor: 'candidates who succeed in associating themselves with one such category enjoy greater success in attracting employers' attention - even though they thereby accept significant restrictions on their future identities' (2003: 1018). There have certainly been points in his career where this has held true for Bean, as the ingrained credibility of his 'Northern everybloke' image is perceived as limiting his range and talent to portraying a succession of 'gruff alpha-cocks' (Moran 2012). More recently, Bean has been able to challenge this preconception. His performance in The Accused (2010-) met with popular and critical acclaim, as Bean shone as both the downtrodden English teacher Simon Gaskell and his sharp-tongued, hyper-feminine alter ego, Tracie Tremarco. Reviews tended to dwell on 
the incongruity of the casting, as seen in The Sheffield Star's focus on 'that famous craggy face, masked with foundation; that gritty Handsworth accent, blanket-stitched with effeminacy' (Davison 2012). There were also inevitable contrasts drawn back to Sharpe: an interview with Saga ran under the byline 'From Sharpe to Stilettos', while The Mirror stuck to 'Bean looks Sharpe in cross-dressing role'. The initial focus is fixed on the gulf between the characters and the extent of Bean's subversion of his usual type of role, but it is also arguable that the real measure of his performance in The Accused is found through the possibility of connection. Without wishing to overstate the case, Tracie is presented as brave, stubborn and painfully aware that being used is not the same thing as being accepted. The role is a departure, but there is something unfortunately patronizing in the reviews that approach it as an anomaly.

In the final analysis, it is clear that his fortuitous portrayal of Sharpe continues to serve as a cornerstone of Bean's career. Sharpe's screen personality, as defined by Bean, has gone on to provide an enduring link between many of the actor's subsequent roles. If it has sometimes led to him being typecast, it has also lent a valuable degree of authority and authenticity to an unexpected range of performances, establishing range as well as consistency, while also ensuring that at least one Bean performance can be safely excluded from his death-reel. Above all, Sharpe was the series that originally enabled the young actor to establish himself as a quintessentially Northern talent, and it remains an essential reference point in any discussion of Sean Bean's regional identity, as well as his global success.

\section{References}

Adkin, M. (2003), The Sharpe Companion: The Early Years, London: HarperCollins. 
Billington, M. (2002), 'Review: Macbeth', The Guardian, 15 November, http://www.theguardian.com/stage/2002/nov/15/theatre.artsfeatures2. Accessed 20 March 2015.

Blandford, L. (2006), Sharp Cut: The Inside Story of the Creation of a Major Television Series, London: HarperCollins.

Cavendish, D. (2011), 'Review: Othello, Sheffield Crucible', The Telegraph, 20 September, http://www.telegraph.co.uk/culture/theatre/theatre-reviews/8778039/OthelloSheffieldCrucible-review.html. Accessed 20 March 2015.

Cornwell, B. (1988), Sharpe's Rifles, London: HarperCollins. (1994), Sharpe's Eagle, London: HarperCollins. (1998), Sharpe's Triumph, London: HarperCollins.

_ (2001), Sharpe's Prey, London: HarperCollins. (2006), Sharpe's Story, London: HarperCollins.

Davison, J. (2012), 'Bean seen anew', The Sheffield Star, 16 August, http://www.thestar.co.uk/what-s-on/bean-seen-anew-1-4836754. Accessed 20 March 2015. 
De Groot, J. (2009), Consuming History: Historians and Heritage in Contemporary Popular Culture, Abingdon: Routledge.

(2010), The Historical Novel, Abingdon: Routledge.

Fletcher, T. (2012), 'All Yorkshiremen are from Yorkshire, but some are more "Yorkshire" than others: British Asians and the myths of Yorkshire Cricket', Sport in Society: Cultures, Commerce, Media, Politics, 15:2, pp. 227-45.

Forwood, M. (1993), 'Bean machine', Daily Express, 1 May, http://www.compleatseanbean.com/bib-sharpe1.html. Accessed 20 March 2015.

Harris, B. R. (1848), The Recollections of Rifleman Harris, London: H. Hurst, https://archive.org/details/recollectionsofr00harr. Accessed 20 March 2015.

Harrison, T. (2013), 'Them and [u]z', Selected Poems, London: Penguin, pp. 110-11.

Jackson, L. (2000), Sean Bean: The Biography, London: Piatkus.

Comment [K18]: Please provide the names of editors: When you do this please follow the following format exactly, including connecting punctuation: Harrison, T. (2013), 'Them and $[\mathrm{u}] \mathrm{z}$ ', in x. x. xxxx and $\mathrm{x}$. xxxx (eds), Selected Poems, London: Penguin, pp. 110-11. 
Jackson, P. (2001), Lord of the Rings: The Fellowship of the Ring, USA. New Line Cinema.

Martin, G. R. R. (2009), 'A casting we will go', Not A Blog, 19 July,

http://grrm.livejournal.com/95840.html. Accessed 20 March 2015.

Moran, C. (2012), 'The Accused review', The Times, 18 August,

http://www.ashleypearce.com/reviews/accused-caitlin-moran-the-times. Accessed 20 March 2015.

Orwell, G. (2001), The Road to Wigan Pier, London: Penguin Classics.

Paterson, E. (1993), 'Rogue male’, Time Out, 26 May,

http://www.compleatseanbean.com/mainfeatures-158.html. Accessed 20 March 2015.

Read, M. (2013), 'What is going on with the accents in Game of Thrones?', Gawker, 5 June, http://gawker.com/what-is-going-on-with-the-accents-in-game-of-thrones485816507. Accessed 20 March 2015

Russell, D. (2004), Looking North: Northern England and the National Imagination, Manchester: Manchester University Press.
Comment [K19]: Please provide the name of the production house. When you do this please follow the following format exactly, including connecting punctuation: Jackson, P. (2001), Lord of the Rings: The Fellowship of the Ring, USA: $\mathrm{xxxxx}$ 
Selcke, D. (2008), 'Promise me, Ned', Winter is Coming, 25 November,

http://winteriscoming.net/2008/11/25/promise-me-ned. Accessed 20 March 2015.

Staples, S. (1995), 'Sean Bean: Straight as steel', Sunday Express Magazine, 8 July, http://www.compleatseanbean.com/mainfeatures-71.html. Accessed 20 March 2015.

Viner, B. (1995), 'Sean Bean: Villain of the year', The Mail on Sunday, 31 December, http://www.compleatseanbean.com/mainfeatures-73.html. Accessed 20 March 2015.

Vitoria, A. (2011), Age of Heroes, UK. Giant Films.

Comment [K20]: Please provide the name of the production house. When you do this please follow the following format exactly, including connecting punctuation: Vitoria, A. (2011), Age of Heroes, UK: $\operatorname{xxxxxx}$

Whitbrook, J. (2014), 'One does not simply assume that Sean Bean always dies', ToyBox io9, 12 July, http://toybox.io9.com. Accessed 20 March 2015.

Zuckerman, E., Kim, T.-Y., Ukanwa, K., von Rittmann, J.et all. (2003), 'Robust identities or nonentities? Typecasting in the feature film labor market', American Journal of Sociology, 108:5, pp. 1018-73.

Television programmes

The Accused (2010-2012, United Kingdom: BBC). 
The Bill (1984-2010, United Kingdom: ITV).

Endeavour (2012-, United Kingdom: BBC).

Game of Thrones (2011-, United States: HBO).

Lady Chatterley (1993, United Kingdom: BBC).

Legends (2014-, United States: Fox 21).

Rock and Chips (2010-2011, United Kingdom: BBC).

Sharpe (1993-2008, United Kingdom: ITV).

'Sharpe’s Rifles' (Series 1, Episode 1)

'Sharpe's Eagle' (Series 1, Episode 2)

Sharpe's Honour (Series 2, Episode 3)

'Sharpe's Regiment' (Series 4, Episode 1)

'Sharpe's Justice' (Series 5, Episode 2)

The Wire (2002-2008, United States: HBO).

\section{Contributor details}

Siân Harris is a Lecturer in English at the University of Exeter. Her research is catalysed by the intersections of gender and genre, with a strong interest in popular culture. Previous publications include an interview with Ian Rankin, a chapter on the significance of food in $\mathrm{J}$. K. Rowling's Harry Potter books, and a reading of the male poet's masculinity in the biopics of Ted Hughes and Dylan Thomas. 
Contact:

c/o Department of English, Queen's Building, University of Exeter, Exeter EX4 4QH,

United Kingdom.

E-mail: S.L.Harris@exeter.ac.uk

Formatted: French (France)

Notes

1 The books do establish that both women come from privileged families, but this is downplayed on-screen.

2 'Sharpe's Gold' (1995) begins with the premise of its namesake novel before veering quickly off into a tale of human sacrifice and Aztec treasure; 'Sharpe's Challenge' (2006) amalgamates three novels, whereas 'Sharpe's Mission' (1996) and 'Sharpe's Peril' (2008) were both written originally for television.

${ }^{3}$ Not only was Pride and Prejudice first published in 1813 - a year before the events of 'Sharpe's Justice' - but the popular Andrew Davies adaptation aired in 1995, and would still be a familiar point of cultural reference for viewers.

${ }^{4}$ Billington's reference to a Geordie (Newcastle) accent is actually a case of mistaken identity - other reviewers confirm Bean used a Yorkshire accent for the part. 